\title{
Preface
}

In the summer of $198_{3}$, a large number of women established the Seneca Women's Encampment for a Future of Peace and Justice near a military nuclear weapons storage depot in Seneca County, New York. There, women gathered to protest nuclear weapons and to critique the "patriarchal society" that created and used those weapons. During that summer the protests led to verbal and physical clashes between the encampment and the people residing in surrounding communities. The encampment became a major regional news event of the summer and was noted regularly in the national media.

This book looks at the conflicts between the women at the encampment and their neighbors, at the strategies these people used to deal with their differences, and at some particularly intense confrontations during which their conflicting views and positions came into play. Both groups found the differences between them very disturbing, but perhaps even more upsetting were the differences within each group. As the events of the summer revealed these differences and forced public acknowledgment of them, deeply held assumptions about what constituted membership in each community were challenged. In emphasizing conflicts and disagreements, however, I do not mean to suggest that only disharmony existed in Seneca County or the women's encampment. Rather, I hope these confrontations can provide a window on our social mechanisms, for these kinds of differences between and within communities are not unique to this set of events; they should be seen as an expected part of social life.

In negotiating their differences, both internal and external, each group attempted to build a coherent identity, to define who they were and to state their place in a confusing and threatening world. To this end, they constructed representations of themselves and the "other," which they used to defend their identities and communities. Here, to analyze the processes involved in building and using these self-representations, I ex- 
amine a wide range of narratives and actions that made up social, psychological, and political dramas.

In the tradition of Arthur Vidich and Joseph Bensman's Small Town in Mass Society (a study conducted in the I950s in a community near Seneca County), this book is concerned with the often uneasy relationship between local communities and the larger society in which they exist. But unlike the earlier study, which took place before the globalization of mass communication and the massive presence of multimedia forms in the home, this book does not assume that mass culture is an "external agent," somehow separable from the local community into which it "transmits" policies and information (I958:82). Instead, all the aspects of mass societies intricately intertwine, generating much confusion and tension in their members, who then try to separate these interwoven aspects of their lives into identifiable communities and influences. Their attempts are what interest me here. I want to understand how people defined and juggled what came to be seen as separate personal, community-based, and mass-culture narratives as they were trying to make sense of the world around them.

The question that arises for an anthropologist studying these events is not who was right and who was wrong but how the participating communities defined all that was happening around them that summer. This book analyzes constructed texts, identities, and narrative representations in order to show their rhetorical composition and the discursive constraints that affected their production and utilization. I conclude that constructing representations is a powerful political act that controls not only the crucial definition of self and other but also the differential access to power, resources, influence, and status.

The results of my work are presented here in the form of an experimental ethnography that employs, at the same time that it is exploring, a variety of textual forms and voices. Such textual experiments are becoming more common in anthropological texts. Myra Bluebond-Langner (1978), for example, uses the same technique of organizing narrative information into the form of a dramatic play that I have employed in Chapter I3. The fictionalized narrative in Chapter I2, though not common in standard ethnography, is being seen more often as anthropologists turn their field experiences into novels (Barbara Tedlock, Billy Jean Isbell, Dan Rose, and others are actively exploring this genre). Even the inclusion of substantial transcripts of conversations and written textual productions of the community under study is still relatively uncommon in ethnography. Peter Davis's portrait of an American community, which com- 
bines "social research with techniques of storytelling" (Davis I982:I0), covering events from a wedding to a murder in a small town, perhaps comes closest to the project attempted here. These experiments in textuality, wedged into more traditional analysis, are designed to demonstrate the complexity of textual production not just in ethnographies but also in the everyday lives of the people anthropologists study.

The events described and analyzed here took place in 1983 , at a time when there was much concern and discussion about the nuclear threat to the world. When events in Europe in 1989 and I 990 signaled the "end" of the cold war, concerns about nuclear weapons and policies came to seem almost unnecessary. Suddenly it seemed as if we could put behind us the powerful cold-war narratives of self and other that had been sustaining and driving us. The attempts to replace these old stories with new narratives of a neutral, unthreatening world were short-lived, and the war in the Persian Gulf brought back in full force the types of narratives described here. I hope this analysis helps the reader to make sense not only of the events of 1983 but of the similar processes of narrative construction and textual self-defense that continue to rule our understanding of the world situation.

My research was conducted in two communities in conflict with each other; yet both encouraged and supported my project. I thank all the women of the Seneca Women's Encampment for a Future of Peace and Justice who were willing to share their experiences, ideas, and written accounts. Some I only know by first name and others are identified this way for anonymity. I particularly thank Jody, Shad, Andrea Doremus, and Pam Flanigan for their comments and interest, and Nancy Zucchino, my video partner. Other women whose support and critical comments were especially helpful were Helen, Didi, Hershey, Skysong, Estelle, Kim, Anet, Woodi, Robin, Judy, and Joan. Jean Aceto provided invaluable newspaper files on the encampment. Sharon Chapman and Lucinda Talbot graciously granted me access to the accounts of their encampment experiences. Michelle Crone deserves special thanks for her years of encouragement, friendship, and caring and for her wisdom in guiding me through alternative women's worlds. The Schlesinger Library at Radcliffe College provided materials from their encampment archives. The Boston Women's Video Collective provided me with copies of their extensive videotape documentation of the encampment, which proved to be extremely valuable.

Residents in and around Seneca County also were willing to share their 
experiences and perceptions, and I especially acknowledge Emerson and Carolyn Moran, Wisner and Barbara Kinne, Jerry McKenna, Joe Bromka, Judy Hart, Terry Mansell, Brian Dombrowski, Howard and Jean Burtless, Nikki Greer, Gwen McLeod-Webber, Ed Polk Douglas, Ferdinand Nicandri, Father Michael Conboy, Father Albert Shamon, Doyle Marquardt, and Robert Zemanek for the time and information they provided. The Seneca County Cooperative Extension and Ray Zajac and Sharon Secor of the Seneca County Board of Supervisors helped with crucial information. Seneca County sheriff Tom Cleere generously gave me access to the records of the events of 1983 and the facilities to study them. Dale Arcangeli, also of the sheriff's department, provided a fascinating orientation to life in Seneca County and was an excellent source of information and reflections.

The men and women of the Waterloo VFW Post made me feel welcome in their community, and my special appreciation goes to Ron and Nancy Bush, and to my friend Barney Olschewske, for all the help they provided. In Waterloo, Melley and Tom Kleman also extended warm hospitality, and Melley was particularly instrumental in integrating me into community life. In this regard I also thank all the women of the weekly Trivial Pursuit games!

In Seneca Falls, Mary Curry was a wonderful source of historical information on women's activities in the area, and Gwen Henderson (pseudonym) provided a moving and significant account of life in her town. Howard Van Kirk, Jr., shared his perceptive observations in an everdelightful manner, and Pam Quiggle provided excellent photographic documentation of the encampment as well as her friendship and an introduction to a softball team in need of another player. My thanks to the women of that team for the chance to participate in another aspect of Seneca County life.

My apologies to any at the encampment and in Seneca County I may have forgotten, and my thanks to some very helpful people who have chosen to remain anonymous.

Members of the Seneca County news media-particularly Dave Shaw of the Syracuse Post-Standard/Herald-Journal, Carol Ritter of the Democrat and Chronicle, Marty Toombs of the Finger Lakes Times, and Bob Appel and Greg Cotteril of radio station WSFW-gave me their time and access to their records. The Auburn Citizen also made its records available.

I thank Roger Sanjek, the editor of this Cornell University Press series, the Anthropology of Contemporary Issues, for excellent guidance in im- 
proving this book and making it accessible to a wider audience. He and an anonymous reader offered perceptive and valuable suggestions.

I thank members of the Department of Anthropology, University at Albany, State University of New York, for general support and also for particular contributions: Gary Gossen for the inspiration to come back into anthropology; Jorge Klor de Alva for introducing me to models of critical thinking; Gail Landsman for suggesting the women's encampment as a topic; Walter Zenner for reminding me of the more general anthropological contexts for my work; and Iris Berger (Department of History) for her careful and perceptive readings and comments. I have been significantly influenced by Helen Elam of the Department of English, University at Albany, who has been instrumental in moving my thinking in exciting and productive directions over the past several years. For this I am particularly grateful.

Many fellow students, friends, and colleagues at the University at Albany, too numerous to mention, provided a valued forum for the discussion of my research. Special thanks do go to Susan Stebbins, Rhonda LaFleur, Laurie Donaldson, and Julie Goodson-Lawes for their discussions and for their visit in the field. Kathy O'Connor made expert transcriptions of my taped interviews as well as humorous, insightful comments throughout the project. Many thanks to Michael Blitz for inspirational conversations and for always knowing what I was saying and doing even when I couldn't figure it out. He continues to be my most important collaborator.

My thanks finally to my family, especially my sister, Joanne Stetson, and my mother, Mary Torok, for always being there and for not asking too often when I would be finished. And special thanks to Richard M. Leventhal, whose generous support and encouragement throughout made my work possible.

This research was funded in part by SUNY Benevolent Association Research Grants from the SUNYA Foundation, and by a grant from the Sigma Xi Grants-in-Aid of Research Program. All photographs not attributed to others are my own.

LOUise KrasNiewicz

Santa Monica, California 



\section{Nuclear Summer}




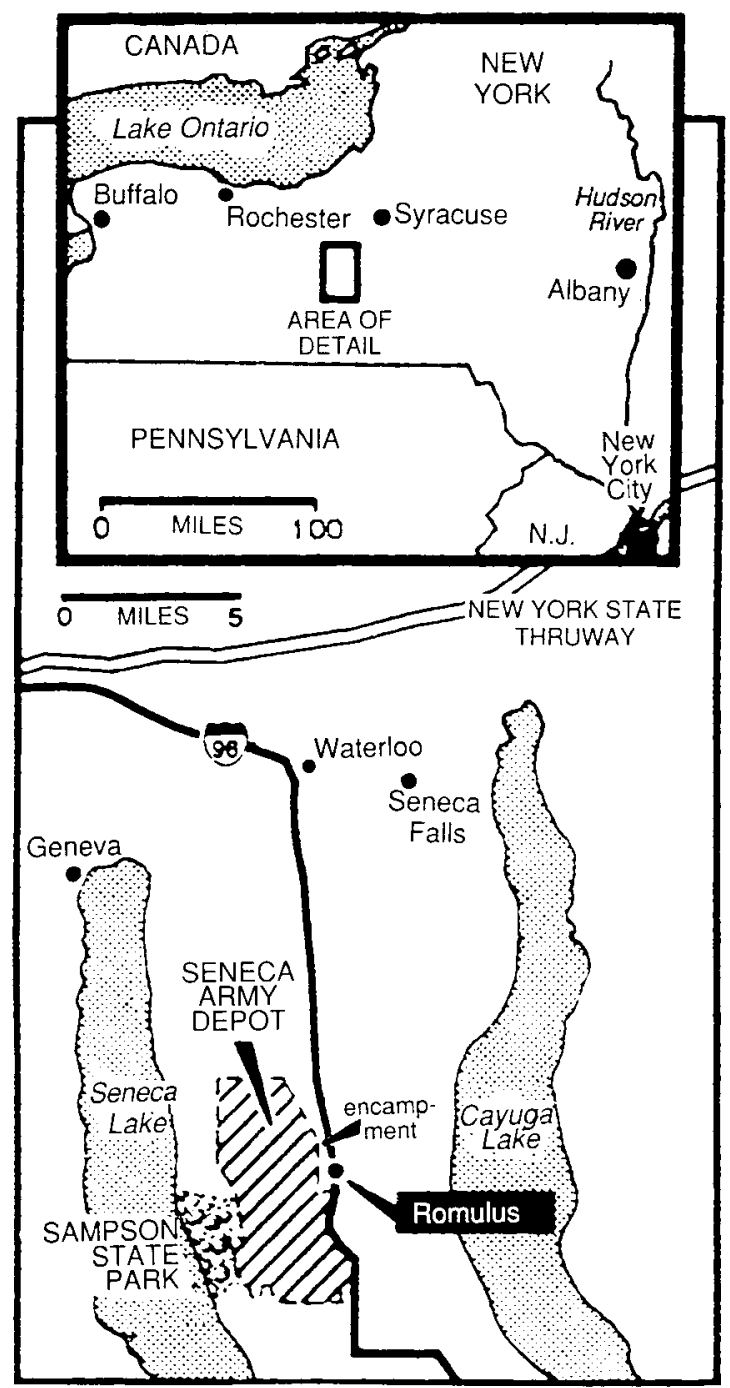

Copyright $(1983$ by the New York Times Company. Reprinted by permission. 